\title{
Resistance to Chloride Ion Permeability of Concrete Mixed with Fly Ash, Slag Powder, and Silica Fume
}

\author{
Chen Wang, Yuanxi Wang, Zhiliang Meng* \\ College of Urban and Construction, Agricultural University of Hebei, Baoding 071001, China
}

Corresponding Author Email: lip19@1zu.edu.cn

https://doi.org/10.18280/acsm.440109

Received: 17 September 2019

Accepted: 10 November 2019

\section{Keywords:}

silica fume, air content, resistance to chloride

ion penetration

\begin{abstract}
This paper attempts to study the resistance to chloride ion permeability of concrete mixed with different admixtures such as fly ash (FA), slag powder (SP), and silica fume (SF). For this, taking the C50 concrete with the 1:1 proportion of FA and SP, the test method for rapid chloride ion migration (RCM) coefficients was used to study the resistance to chloride ion permeability and economic benefits of the concrete under the conditions of different total amount of admixtures, SF content, and air content. The results show that the increase in the total amount of the admixture can improve the concrete resistance to chloride ion penetration, but in a gradually weakening trend; the increase in SF content can increase the concrete resistance to chloride ion penetration, but the enhancement effect is gradually decreased; the SF has more significant effect on improving the 56d concrete resistance to chloride ion penetration; the increase of air content greatly increases the chloride ion migration coefficient of concrete at $28 \mathrm{~d}$, and the chloride ion migration coefficient increases linearly at $56 \mathrm{~d}$; the air content within $5 \%$ has an insignificant effect on the resistance to the chloride ion permeability; the NH40-2 was chosen to be the optimal mix ratio.
\end{abstract}

\section{INTRODUCTION}

At present, concrete is one of the most widely used building materials. As its service life increases, reinforced concrete (RC) structures are subjected to a series of durability problems, including concrete carbonation, reinforcement bar corrosion, freeze-thaw failure, alkali aggregate reaction, Sulfate erosion, and fatigue damage, etc. [1-5]. Among them, internal corrosion of reinforcement bar caused by chloride penetration can lead to the most serious RC structural damage, which is also the most common in engineering structures [6-11].

Adding an appropriate amount of admixture to concrete can help improve its resistance to the chloride ion penetration [12, 13], and then effectively improve the durability of concrete. In recent years, scholars at home and abroad have conducted many researches on the resistance of concrete to chloride ion penetration. Some scholars studied the effect of FA and SF on the chloride ion permeability and found that the pore structure of concrete and its binding ability with chloride ion are the main influencing factors on the chloride ion permeability [14]; Seleem et al. [15] studied the chloride ion permeability to multi-doped concrete with the SF, ground blast furnace slag, and metakaolin as cementitious materials, indicating the cementing material system composed of cement and SF is the most effective combination to resist the chloride ion penetration. Related research through analysis for the chloride ion permeability of concrete mixed with FA and slag, concluded that the effect of slag on the resistance of selfcompact concrete to chloride ion penetration is better than that of FA, and the additive effect of mixtures on this resistance is not obvious [16]; Guo et al. [17] conducted orthogonal experiments and studied the effects of water-binder ratio, FA content, water consumption, and air entrainer content on the resistance of bridge concrete to the chloride ion penetration, finding that FA has a significant effect on the resistance of concrete to chloride ion penetration, and proper air content can also improve this. Currently, the research on the resistance of concrete to chloride ion penetration mostly focuses on singleor double-mixed concrete [18-20], but little research has been done on concrete with three kinds of admixtures.

FA and SP are common industrial waste materials, which are easy to obtain and low in cost. They can be added to concrete and replace part of the cement for enhancing the compactness of concrete [21-24]. SF is a kind of ultra-active ultrafine siliceous powder material produced in industrial smelting, with an average particle size of less than $0.1 \mu \mathrm{m}$. It has a good capillary porosity filling effect, significantly improving the microscopic pore structure of concrete [25]. Therefore, by adding FA, SP and SF to C50 concrete, the authors studied the effects of different amount of admixtures, SF content, and air content on the resistance of concrete to the chloride ion penetration, and then concluded the optimal mix ratio of concrete with good chloride ion penetration resistance and low cost. This not only increases the service life of the concrete structure, but also reduces its cost.

\section{TEST OVERVIEW}

\subsection{Test specimen design}

First, fabricate the cylindrical pieces with a diameter of $100 \mathrm{~mm} \times 200 \mathrm{~mm}$, and then take out the specimen with a height of $50 \pm 2 \mathrm{~mm}$ from the center. 
Cement: Taihangshan P.O 42.5 ordinary Portland cement.

Fly ash: Class II, from the concrete mixing station of Hebei Construction Group.

Slag powder: S95 grade from the concrete mixing station of Hebei Construction Group.

Silica fume: off-white powder, apparent density: $2200 \mathrm{~kg} / \mathrm{m}^{3}$, $\mathrm{SiO}_{2}$ content: $95.6 \%$.

Fine aggregate: river sand, with fineness modulus 2.71, medium sand; apparent density $2655 \mathrm{~kg} / \mathrm{m}^{3}$, clay content $1.3 \%$, and clay lump content 0 .

Coarse aggregate: 5 to $20 \mathrm{~mm}$ continuous grading crushed stone, with apparent density: $2715 \mathrm{~kg} / \mathrm{m}^{3}$, crushing index $7 \%$, total content of needle-like particles $3.6 \%$, clay content $0.8 \%$, and clay lump content 0 .

Water reducer: polycarboxylic acid-based high-efficiency superplasticizer with the solid content of $40 \%$, from Baoding
Muhu Hengyuan New Building Material Co., Ltd.

Air-entrainer: AE-P air-entraining agent produced by a Japanese company.

The water-binder ratio was adjusted to ensure that the concrete can meet the requirements of C50 strength grade; the proportion of FA and SP was fixed to 1: 1, and the same amount of mineral admixture replaced $30 \%, 40 \%$ and $50 \%$ of cement, of which the SF content was $5 \%$; with the total amount of mineral admixture for $40 \%$ of cement, the SF content was $0 \%, 2.5 \%$, and $5 \%$; with the total amount of mineral admixture for $40 \%$ and the content of SF for $5 \%$, the air content was $3 \%$, $4 \%$ and $5 \%$ respectively. The amount of polycarboxylic acid superplasticizer was also adjusted to meet the requirements of large fluidity in concrete mixture. The mix ratio of C50 concrete is shown in Table 1.

Table 1. Concrete mix ratio

\begin{tabular}{|c|c|c|c|c|c|c|c|c|c|c|c|}
\hline \multirow[b]{2}{*}{ No } & \multirow[b]{2}{*}{$\begin{array}{c}\text { Water- } \\
\text { binder ratio }\end{array}$} & \multicolumn{6}{|c|}{ Amount of materials $/ \mathrm{kg} / \mathrm{m}^{3}$ ) } & \multirow[b]{2}{*}{$\begin{array}{l}\text { Water content } \\
\qquad /(\%)\end{array}$} & \multirow[b]{2}{*}{$\begin{array}{l}\text { Sand } \\
\text { ratio }\end{array}$} & \multirow[b]{2}{*}{$\begin{array}{l}\text { Slumps / } \\
(\mathbf{m m})\end{array}$} & \multirow[b]{2}{*}{$\begin{array}{c}\text { Compressive strength / } \\
(\mathrm{MPa})\end{array}$} \\
\hline & & $\begin{array}{l}\text { Fly } \\
\text { ash }\end{array}$ & $\begin{array}{c}\text { Slag } \\
\text { powder }\end{array}$ & $\begin{array}{l}\text { Silica } \\
\text { fume }\end{array}$ & Sanf Stone & Water & $\begin{array}{l}\text { Water } \\
\text { reducer }\end{array}$ & & & & \\
\hline HN30-1 & 0.40 & 53 & 53 & 21 & 7561044 & 170 & 2.1 & - & $42 \%$ & 203 & 64.58 \\
\hline HN40-1 & 0.38 & 80 & 80 & 23 & 7331012 & 175 & 2.3 & - & $42 \%$ & 215 & 62.25 \\
\hline HN40-2 & 0.34 & 92 & 92 & 12 & 7311009 & 165 & 2.7 & - & $42 \%$ & 212 & 66.53 \\
\hline HN40-3 & 0.33 & 100 & 100 & 0 & 7281005 & 165 & 2.5 & - & $42 \%$ & 228 & 62.13 \\
\hline HY40-1 & 0.38 & 80 & 80 & 23 & 7331012 & 175 & 2.3 & 3 & $42 \%$ & 218 & 60.29 \\
\hline HY40-2 & 0.38 & 80 & 80 & 23 & 7331012 & 175 & 2.3 & 4 & $42 \%$ & 220 & 62.89 \\
\hline HY40-3 & 0.38 & 80 & 80 & 23 & 7331012 & 175 & 2.3 & 5 & $42 \%$ & 225 & 62.03 \\
\hline HN50-1 & 0.37 & 104 & 104 & 23 & $732 \quad 1011$ & 170 & 2.0 & - & $42 \%$ & 213 & 63.12 \\
\hline
\end{tabular}

Note: $\mathrm{HN} \times \times$ means no air-entraining agent, $\mathrm{HY} \times \times$ means air-entraining agent added, and 30, 40, 50 means that the total amount of admixtures is $30 \%, 40 \%$ and $50 \%$ respectively.

\subsection{Test method}

According to the Standard for Test Method of Long-term Performance and Durability of Ordinary Concrete (GB/T50082-2009) [26], test method for rapid chloride ion migration coefficient (RCM) was used to measure the chloride ion permeability coefficients of concrete in the age of $28 \mathrm{~d}$ and $56 \mathrm{~d}$. The ordinary concrete at $28 \mathrm{~d}$ can reach the design value of compressive strength. Because the strength of concrete mixed with mineral admixture increases slowly, 56d was taken as the detection age. After the test specimens reached the age, they were taken out of the curing tank, and measured in terms of their diameter and height. Then, the test specimens were placed in a concrete vacuum saturated machine (Figure 1) and treated with a saturated calcium hydroxide solution in distilled water. After the vacuum treatment, the specimen was placed in the bottom of the rubber sleeve, and the outer side of the rubber sleeve was tightly covered with a stainless steel hoop, to ensure the side of the specimen in a sealed state. Next, install the RCM device (Figure 2), inject $300 \mathrm{~L}$ of $0.3 \mathrm{~mol} / \mathrm{L} \mathrm{NaOH}$ solution into the rubber sleeve and immerse the anode plate and the specimen, and then inject $12 \mathrm{~L}$ of $10 \% \mathrm{NaCl}$ solution into the cathode test tank. Thus, the test started. After the test, the specimens were cut along the axis, and the split surface was sprayed with the discolored indicator of $\mathrm{AgNO}_{3}$ solution with a concentration of $0.1 \mathrm{~mol} / \mathrm{L}$. The discolored surface was divided into 10 equal sections, and the distance of color boundary from the bottom of the specimen is the depth of chloride ion penetration (Figure 3 ).

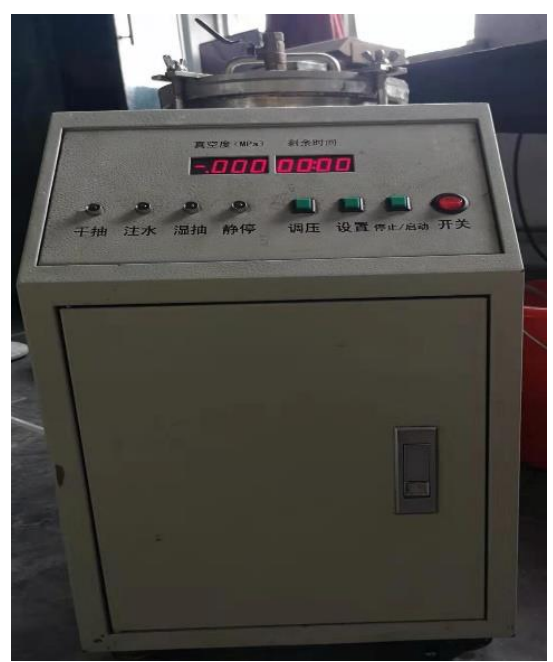

Figure 1. Concrete vacuum saturated machine

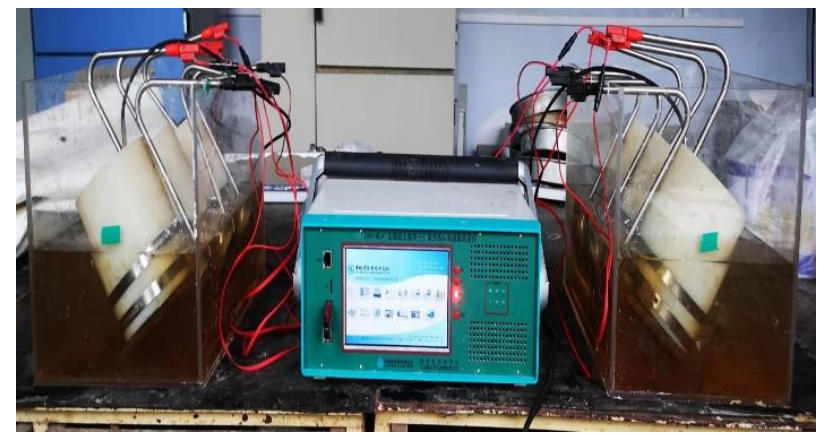

Figure 2. RCM device 


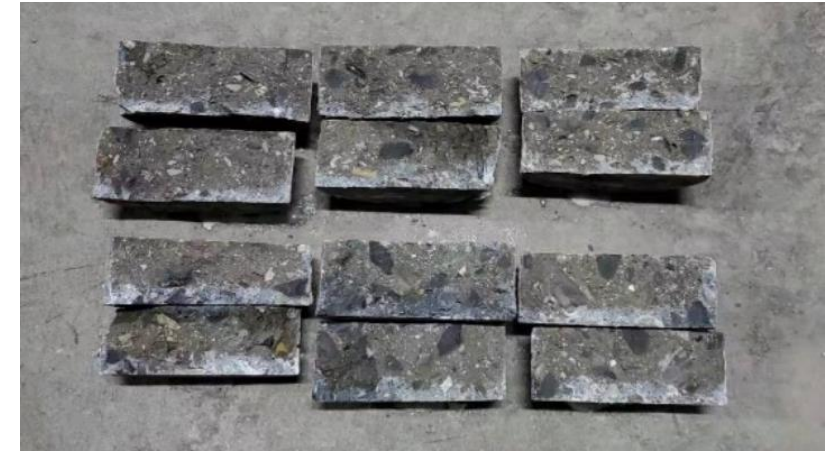

Figure 3. Discolored specimens

According to the recorded data, the unsteady chloride ion migration coefficient of concrete is calculated as:

$$
D_{R C M}=\frac{0.0239 \times(273+T) L}{(U-2) t}\left(X_{d}-0.0238 \sqrt{\frac{(273+T) L X_{d}}{U-2}}\right)
$$

where:

$D_{R C M}$ : Unsteady chloride ion migration coefficient of concrete, with the accuracy of $0.1 \times 10^{-12} \mathrm{~m}^{2} / \mathrm{s}$;

$U$ : The absolute value of the voltage $(\mathrm{V})$;

$T$ : The average value of the initial temperature and the end temperature of the anode solution $\left({ }^{\circ} \mathrm{C}\right)$;

$L$ : Thickness of test piece $(\mathrm{mm})$, with the accuracy of $0.1 \mathrm{~mm}$;

$X_{d}$ : The average value of chloride ion penetration depth (mm), accurate to $0.1 \mathrm{~mm}$;

$t$ : Test hours (h).

\section{TEST RESULTS AND ANALYSIS}

\subsection{Effects of total amount of admixture on resistance to chloride ion penetration of $\mathbf{C 5 0}$ concrete}

Under the conditions of the C50 strength grade, the 1:1 proportion of $\mathrm{FA}$ and SP, and 5\% SF content, the chloride ion migration coefficients at $28 \mathrm{~d}$ and $56 \mathrm{~d}$ of $\mathrm{HN} 30-1$, HN40-1, and HN50-1 are shown in Table 2 and Figure 4.

It can be seen from Figure 4 that for concrete of the same strength, as the total amount of admixture increased, the FA and SP also increased relatively and the resistance to chloride ion migration coefficients of concrete at $28 \mathrm{~d}$ and $56 \mathrm{~d}$ continued to decrease. Compared with HN30-1, the chloride ion migration coefficients of HN40-1 at 28d and 56d decreased by $33.9 \%$ and $36.3 \%$, respectively; compared with HN40-1, the chloride ion migration coefficients of HN50-1 at 28d and $56 \mathrm{~d}$ decreased by $15.0 \%$ and $14.2 \%$. Compared with existing research results, this can more clearly indicate that the chloride ion migration coefficient of concrete decreased more slowly when the total amount of the admixture increased from $40 \%$ to $50 \%$ than from $30 \%$ to $40 \%$.

This indicates that with the same concrete strength grade, certain SF content, and the same proportion of FA and SP, the concrete with $50 \%$ total admixture has better resistance to chloride ion penetration than $30 \%$ and $40 \%$. The increase of the total amount of admixture can improve the resistance to chloride ion penetration, but at a gradually weakening rate. This is mainly because the increase in the total amount of admixtures for the same strength grade of concrete will lead to three phenomena: a decrease in the water-to-binder ratio to varying degrees, an improvement in the micro-aggregate filling effect of admixtures, and a decline in the secondary hydration micro-filling effect of the admixture; the former two decreased the chloride ion migration coefficient of the concrete, while the last one increased this coefficient. Therefore, with the increase of the total admixture, the effects of the former two factors on reducing the concrete resistance to chloride ion migration coefficients are far greater than that of third factor, so the combined effects of various factors can greatly enhance the resistance of concrete to chloride ions; also, when the total admixture continues to increase, the effect of the third factor on increasing the chloride ion migration coefficient will gradually increase, so the combined effect of various factors will slow down the increase in the resistance of concrete to chloride ion.

Table 2. The chloride ion migration coefficients of concrete $\mathrm{D}_{\mathrm{RCM}} 10^{-12} \mathrm{~m}^{2} / \mathrm{s}$

\begin{tabular}{lccc}
\hline No. & HN30-1 & HN40-1 & HN50-1 \\
\hline 28d & 3.073 & 2.031 & 1.727 \\
$56 \mathrm{~d}$ & 2.049 & 1.306 & 1.121 \\
\hline
\end{tabular}

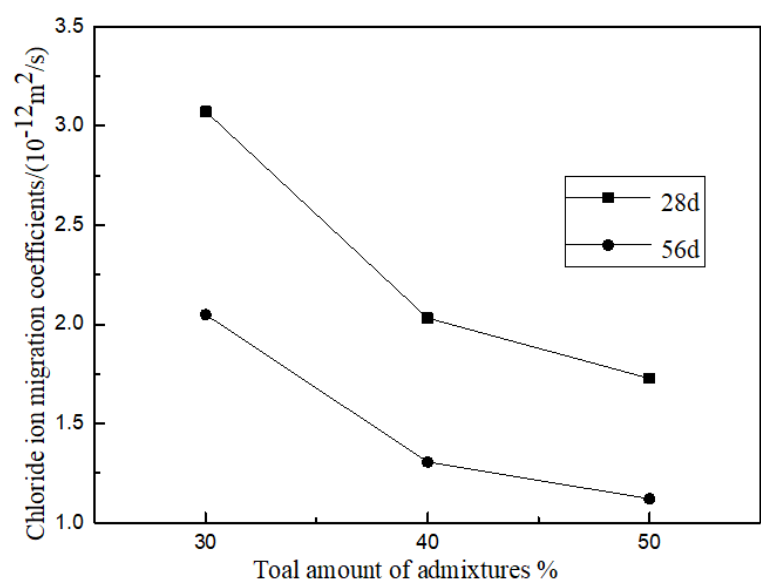

Figure 4. Effects of total amount of admixtures on chloride ion migration coefficients

\subsection{Effect of silica fume content on resistance to chloride ion penetration of $\mathbf{C 5 0}$ concrete}

Under the conditions of the C50 strength grade, the 1:1 proportion of FA and SP, and $0 \%, 2.5 \%$, and $5 \%$ SF content, the chloride ion migration coefficients at $28 \mathrm{~d}$ and $56 \mathrm{~d}$ of HN40-1, HN40-2, and HN40-3 are shown in Table 3 and Figure 5.

It can be seen from Figure 5 that the addition of SF has a significant effect on the chloride ion migration coefficient of C50 concrete. When the total amount of the admixture was $40 \%$, with the increase of the SF content, the admixture amount of FA and SP relatively decreased, the chloride ion migration coefficients of C50 concrete on $28 \mathrm{~d}$ and $56 \mathrm{~d}$ decreased, and the resistance of concrete to chloride ion penetration gradually increased.

With the addition of SF, the chloride ion migration coefficient on $56 \mathrm{~d}$ of the Hd40-1 with $5 \%$ SF decreased by $14.7 \%$, and the coefficient on $56 \mathrm{~d}$ decreased by $33.1 \%$, compared to HN40-3 without SF. This shows that the addition of SF below $5 \%$ can improve the resistance to chloride ion penetration of concrete at $56 \mathrm{~d}$ more significantly than that at $28 \mathrm{~d}$. When the SF content in concrete increased from no SF in 
HN40-3 to $2.5 \%$ in HN40-2 and then to $5 \%$ in HN40-1, the $28 \mathrm{~d}$ chloride ion migration coefficient of concrete decreased from $13.1 \%$ to $1.8 \%$; the $56 \mathrm{~d}$ coefficients decreased from $26.6 \%$ to $8.9 \%$. The results clearly indicate that when the SF content is below $5 \%$, the effect of SF on the chloride ion migration coefficient gradually decreases, while the effect on enhancing the resistance of concrete to chloride ion penetration gradually weakens.

This is because of the small particle size of SF, 100 times smaller than that of cement. The particle filling effect of SF is conductive to filling the pores of relatively large particles in cementitious material and reduce the volume of capillary pores in concrete, thereby making concrete more compact; the nucleation effect of SF is wrapped around the particles of other cementitious materials, which causes the cement to undergo hydration reaction and produce smaller $\mathrm{CH}$ crystals; also, the fibrous CSH glue caused by the pozzolanic activity effect of SF makes the micro-pore structure of concrete compact and dense.

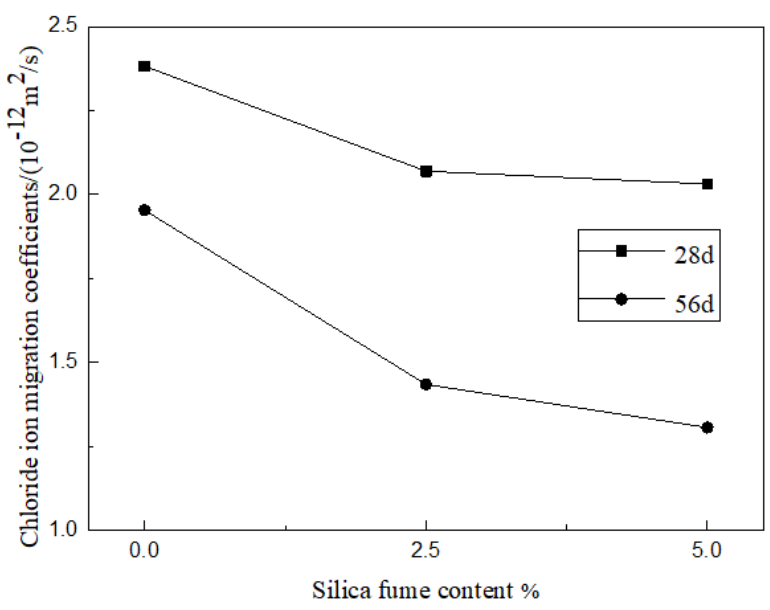

Figure 5. Effects of silica fume content on chloride ion penetration coefficients

Table 3. Concrete chloride ion penetration coefficients $\mathrm{D}_{\mathrm{RCM}}$ $10^{-12} \mathrm{~m}^{2} / \mathrm{s}$

\begin{tabular}{llll}
\hline \multicolumn{4}{l}{ No. HN40-1 HN40-2 } \\
\hline 28N40-3 & 2.031 & 2.069 & 2.382 \\
56d & 1.306 & 1.434 & 1.953 \\
\hline
\end{tabular}

\subsection{Effects of air content on resistance to chloride ion penetration of $\mathbf{C 5 0}$ concrete}

Under the conditions of the C50 strength grade, the $1: 1$ proportion of FA and SP, 5\% SF content, and the air content of $3 \%, 4 \%$, and $5 \%$, the chloride ion migration coefficients at 28d and 56d of HY40-1, HY40-2, and HY40-3 are shown in Table 4 and Figure 6.
Table 4. Concrete chloride ion migration coefficients $\mathrm{D}_{\mathrm{RCM}}$ $10^{-12} \mathrm{~m}^{2} / \mathrm{s}$

\begin{tabular}{cccc}
\hline No. & HY40-1 & HY40-2 & HY40-3 \\
\hline 28d & 2.233 & 2.408 & 2.795 \\
$56 \mathrm{~d}$ & 1.372 & 1.517 & 1.629 \\
\hline
\end{tabular}

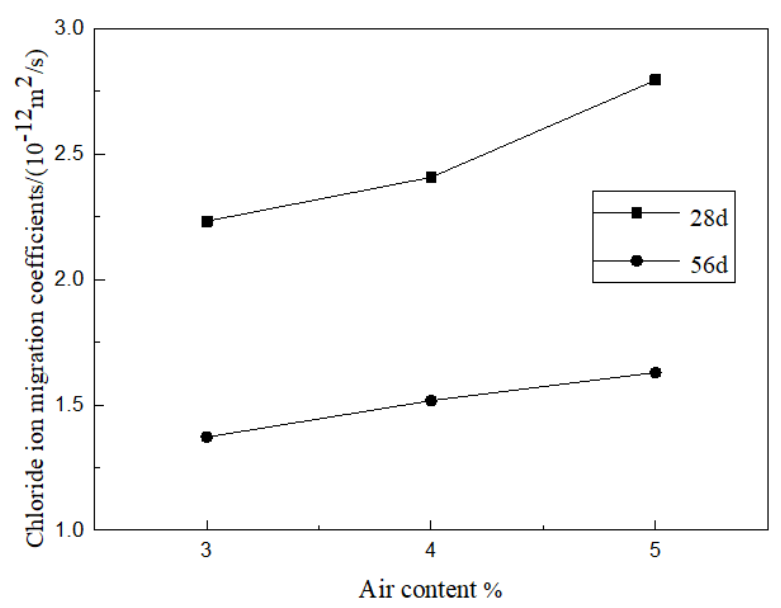

Figure 6. Effects of air content on chloride ion migration coefficients

It can be seen from Figure 6 that under the same conditions above, $28 \mathrm{~d}$ and $56 \mathrm{~d}$ chloride ion migration coefficients of C50 concrete increased with the increase of air content. Compared with HY40-1 with 3\% air content, the $28 \mathrm{~d}$ chloride ion migration coefficient of HY $40-2$ with $4 \%$ air content increased by $7.8 \%$, while compared to HY40-2, that of the HY40-3 with $5 \%$ air content increased by $16.1 \%$. With the increase of air content, the $28 \mathrm{~d}$ chloride ion migration coefficient of concrete doubled, and the $56 \mathrm{~d}$ coefficient continued to increase linearly.

Compared to HN40-1 without air entrainer, the chloride ion diffusion coefficients on $28 \mathrm{~d}$ and $56 \mathrm{~d}$ of HY40-1 with $3 \%$ air content, HY 40-2 with 4\% and HY40-3 with 5\% all increased below $0.7 \times 10^{-12} \mathrm{~m}^{2} / \mathrm{s}$, meeting the current requirements of RCM-IV about resistance to chloride ion penetration of readymixed concrete. Compared with the existing research results, it shows more specifically that the air content below 5\% has no significant effect on the concrete resistance to chloride ion penetration. This is because the increase in air content changes the microscopic pore structure of the concrete, so that the capillary porosity and the capillary pore volume increases, and the concrete resistance to chloride ion penetration decreases.

\section{ECONOMIC BENEFITS}

The unit prices of concrete raw materials were from the market inquiry in 2019. Table 5 lists the amount and cost per cubic meter of concrete raw materials.

Table 5. Concrete cost per cubic meter

\begin{tabular}{|c|c|c|c|c|c|c|c|c|c|c|c|c|c|}
\hline \multirow{2}{*}{ No. } & \multicolumn{6}{|c|}{ Use of concrete raw materials $\left(\mathrm{kg} / \mathrm{m}^{3}\right)$} & \multicolumn{6}{|c|}{ Unit price of concrete raw material (Yuan/on) } & \multirow{2}{*}{$\begin{array}{c}\text { Cost per cubic } \\
\text { meters }\end{array}$} \\
\hline & Cemen & tFly ash & Slay powder & Silicon fume & e Sand & Stone & Cement & Fly ash & Slay powder & Silicon fume & e Sand & Stone & \\
\hline$\overline{\mathrm{HN} 30-1}$ & 296 & 53 & 53 & 21 & 756 & 1044 & 400 & 120 & 320 & 2000 & 113 & 87 & 360.32 \\
\hline HN40-1 & 274 & 80 & 80 & 23 & 733 & 1012 & 400 & 120 & 320 & 2000 & 113 & 87 & 361.10 \\
\hline HN40-2 & 295 & 92 & 92 & 12 & 731 & 1009 & 400 & 120 & 320 & 2000 & 113 & 87 & 353.55 \\
\hline HN40-3 & 300 & 100 & 100 & 0 & 728 & 1005 & 400 & 120 & 320 & 2000 & 113 & 87 & 333.64 \\
\hline HN50-1 & 231 & 104 & 104 & 23 & 732 & 1011 & 400 & 120 & 320 & 2000 & 113 & 87 & 354.96 \\
\hline
\end{tabular}


Table 5 shows that with no SF in NH40-3 and the highest SF content in NH40-1, NH40-2 had the lowest cost, NH40-1 had the highest, and NH40- 2 was 1.41 yuan lower than the NH50-1. Meanwhile, the 56d chloride ion migration coefficients of NH40-1, NH40-2 and NH50-1 all meet the $\mathrm{RCM}-\mathrm{V}$ requirements. Considering the concrete' resistance to chloride ion penetration, the NH40-2 was chosen as the optimal mix ratio.

\section{CONCLUSIONS}

(1) With the same strength grade of C50, and the same proportion of FA and SP, the resistance to chloride ion penetration of concrete with total admixtures of $50 \%$ is better than $30 \%$ and $40 \%$; the increase in the total amount of the admixture can improve the resistance to chloride ion penetration, but at a gradually decreasing rate.

(2) For concrete of the same strength grade, the same amount of admixture, and fixed proportion of FA and SP, an increase in the SF content can improve the concrete resistance to chloride ion penetration; when the SF content is within 5\%, the effect of SF on strengthening the concrete resistance to chloride ion penetration gradually weakens with the increase of the SF; the SF doped below 5\% can improve the chloride ion penetration resistance of concrete at $56 \mathrm{~d}$ more significantly than that at $28 \mathrm{~d}$.

(3) Under the conditions of the same admixture content, 1:1 proportion of FA and SP, and SF content of $5 \%$, the $28 \mathrm{~d}$ chloride ion migration coefficient of concrete of the same strength grade increases with the air content, ranging $7.8 \%$ to $16.1 \%$, and the $56 \mathrm{~d}$ chloride ion migration coefficient increases linearly; the chloride ion migration coefficient of concrete with an air content below 5\% increases within $0.7 \times 10-12 \mathrm{~m} 2 / \mathrm{s}$, which has no significant effect on concrete resistance to chloride ion penetration.

(4) Taking the concrete's resistance to chloride ion penetration and economic benefits into comprehensive consideration, the NH40-2 was chosen as the optimal mix ratio design.

\section{ACKNOWLEDGEMENT}

This paper was supported by Subsidized Project of Innovative Ability Training for Postgraduates in Hebei Provincial Education Department (CXZZSS2019058).

\section{REFERENCES}

[1] Wang, Y., An, M.Z., Yu, Z.R., Han, S., Ji, W.Y. (2017). Durability of reactive powder concrete under chloridesalt freeze-thaw cycling. Materials and Structures, 50(1): 444-452. http://dx.doi.org/10.1617/s11527-016-0878-5

[2] Gu, C., Sun, W., Guo, L., Wang, Q. (2016). Effect of curing conditions on the durability of ultra-high performance concrete under flexural load. Journal of Wuhan University of Technology-Mater. Sci. Ed., 31(2), 278-285. http://dx.doi.org/10.1007/ s11595-016-1365-0

[3] Gökçe, H.S., Öztürk, B.C., Çam, N.F., Andiç-Çakır, Ö. (2018). Gamma-ray attenuation coefficients and transmission thickness of high consistency heavyweight concrete containing mineral admixture. Cement and
Concrete Composites, 92: 56-69. http://dx.doi.org/10.1016/j.cemconcomp.2018.05.015

[4] Zhuang, S.Y., Wang, Q., Zhou, Y.Q. (2019). Research on the resistance to saline soil erosion of high-volume mineral admixture steam-cured concrete. Construction \& Building Materials, 202: 1-10. http://dx.doi.org/10.1016/j.conbuildmat.01.012

[5] Yang, L., Ma, Q., Yu, B. (2018). Analytical solution and experimental validation for dual time-dependent chloride diffusion in concrete. Construction and Building Materials, 161: 676-686. http://dx.doi.org/10.1016/j.conbuildmat.2017.11.176

[6] Zidol, A., Tognonvi, M.T., Tagnit-Hamou, A. (2017). Effect of glass powder on concrete sustainability. New Journal of Glass and Ceramics, 7(2): 75984. http://dx.doi.org/10.4236/njgc.2017.72004

[7] Li, K., Zhang, D., Li, Q., Fan, Z. (2019). Durability for concrete structures in marine environments of HZM project: Design, assessment and beyond. Cement and Concrete Research, 115: 545-558. https://doi.org/10.1016/j.cemconres.2018.08.006

[8] Zhang, P., Hou, D., Liu, Q., Liu, Z., Yu, J. (2017). Water and chloride ions migration in porous cementitious materials: An experimental and molecular dynamics investigation. Cement and Concrete Research, 102: 161174. http://dx.doi.org/10.1016/j.cemconres.2017.09.010

[9] Li, Q., Li, K., Zhou, X., Zhang, Q., Fan, Z. (2015). Model-based durability design of concrete structures in Hong Kong-Zhuhai-Macau sea link project. Structural Safety, 53: 1-12. http://dx.doi.org/10.1016/j.strusafe.2014.11.002

[10] Mehta, P.K., Monteiro, P.J.M. (2014). Concrete: Micro Structure, Properties and Materials. New York, USA: McGraw-Hill Education Press.

[11] Li, K., Wang, P., Li, Q., Fan, Z. (2016). Durability assessment of concrete structures in HZM sea link project for service life of 120 years. Materials and Structures, $\quad 49(9)$ : 3785-3800. http://dx.doi.org/10.1617/s11527-015-0754-8

[12] Saito, J. (2012). Experimental study on the chloride permeability of plate concrete with cracks. Journal of Research Institute of Science and Technology, College of Science and Technology, Nihon University, 2012(127): 127_1-127_10.

[13] Hassan, K.E., Cabrera, J.G., Maliehe, R.S. (2000). The effect of mineral admixtures on the properties of highperformance concrete. Cement and concrete composites, 22(4): 267-271. http://dx.doi.org/10.1016/S0958-9465 (00)00031-7

[14] Peng, G.F., Jiang, Y.C., Li, B.H., Zhang, J., Shi, Y.X. (2014). Effect of high temperature on normal-strength high-performance concrete. Materials Research Innovations, $\quad 18(\mathrm{~S} 2)$ : $\quad$ S2-290-S2-293. https://doi.org/10.1179/1432891714Z.000000000414

[15] Seleem, H.E.D.H., Rashad, A.M., El-Sabbagh, B.A. (2010). Durability and strength evaluation of highperformance concrete in marine structures. Construction and building Materials, 24(6): 878-884. https://doi.org/10.1016/j.conbuildmat.2010.01.013

[16] Uysal, M., Yilmaz, K., Ipek, M. (2012). The effect of mineral admixtures on mechanical properties, chloride ion permeability and impermeability of self-compacting concrete. Construction and Building Materials, 27(1): 263-270. 
https://doi.org/10.1016/j.conbuildmat.2011.07.049

[17] Guo, Y.C., Shen, A.Q., Wang, J., Zhao, H.J. (2014). Resistance to chloride ion permeation to concrete bridges in alpine regions. Journal of Building Materials, 17(3): 425-436. 9629.2014.03.010

[18] Shi, M., Qiang, W., Zhou, Z. (2015). Comparison of the properties between high-volume fly ash concrete and high-volume steel slag concrete under temperature matching curing condition. Construction and Building Materials, 98 .

649-655. http://dx.doi.org/10.1016/j.conbuildmat.2015.08.134

[19] Gholampour, A., Ozbakkaloglu, T. (2017). Performance of sustainable concretes containing very high volume Class-F fly ash and ground granulated blast furnace slag. Journal of Cleaner Production, 162: 1407-1417. http://dx.doi.org/10.1016/j.jclepro.2017.06.087

[20] Bostanc1, Ş.C., Limbachiya, M., Kew, H. (2016). Portland slag and composites cement concretes: engineering and durability properties. Journal of Cleaner Production, 112: 542-552. https://doi.org/10.1016/j.jclepro.2015.08.070

[21] Ma, K., Feng, J., Long, G., Xie, Y., Chen, X. (2017). Improved mix design method of self-compacting concrete based on coarse aggregate average diameter and slump flow. Construction and Building Materials, 143:
566-573.

http://dx.doi.org/10.1016/j.conbuildmat.2017.03.142

[22] Rajasekar, A., Arunachalam, K., Kottaisamy, M., \& Saraswathy, V. (2018). Durability characteristics of Ultra High Strength Concrete with treated sugarcane bagasse ash. Construction and Building Materials, 171: 350-356. http://dx.doi.org/10.1016/j.conbuildmat.2018.03.140

[23] Alkaysi, M., El-Tawil, S., Liu, Z., Hansen, W. (2016). Effects of silica powder and cement type on durability of ultra high performance concrete (UHPC). Cement and Concrete Composites, 66: 47-56. http://dx.doi.org/10.1016/j.cemconcomp.2015.11.005

[24] Ghafari, E., Arezoumandi, M., Costa, H., Julio, E. (2015). Influence of nano-silica addition on durability of UHPC. Construction and Building Materials, 94: 181-188. http://dx.doi.org/10.1016/j.conbuildmat.2015.07.009

[25] Liu, B.Y., Li, K., Zhao, S.C. (2011) Study of effects on chloride resistance to ion penetration and frost of concrete mixed with fly ash and silica fume. Concrete, 2011(11): 83-85. http://dx.doi.org/10.3969/j.issn.10023550.2011 .11 .025

[26] Standard for Test Methods of Long-Term Performance and Durability of Ordinary Concrete (GB/T50082-2009) (2009). China Architecture and Building Press, Beijing (China). 